\title{
EFEITO DO ENSINO EXPLÍCITO NO DESEMPENHO EM LIBRAS: UM ESTUDO COM QUATRO APRENDIZES DE L2
}

\author{
EFFECT OF EXPLICIT TEACHING ON LIBRAS PERFORMANCE: \\ A STUDY WITH FOUR L2 LEARNERS
}

Lídia da Silva*

\section{RESUMO}

O ensino explícito, segundo Alves (2004), Gauthier (2014), Rodrigues e Preuss (2018) e outros, é uma eficiente possibilidade pedagógica para aquisição de elementos linguísticos da L2. Para Silva (2018), o desempenho na Língua Brasileira de Sinais (Libras) pode ser examinado a partir do uso do mapeamento espacial (ME), constituído por elementos da referenciação nominal, da produção morfossintática e da referenciação por meio do corpo. O presente estudo teve como objetivo investigar o efeito do ensino explícito no desempenho em Libras como L2. A pesquisa-ação caracterizou-se pela intervenção com duas turmas de aprendizes de Libras de nível intermediário, sendo que em uma delas houve o ensino explícito do ME. Os participantes realizaram o pré- e o pós-teste, que consistiu na sinalização de uma narrativa. O relato apresentado reporta os dados de duas participantes de cada turma. Os resultados mostram que não houve efeito da instrução explícita no uso da referenciação nominal e por meio do corpo. Quanto à produção morfossintática não houve evidência suficiente para confirmar a melhora no desempenho. Em geral, não foi observado efeito do ensino explícito no desempenho em Libras como L2, o que pode ser parcialmente explicado pela falta de interação decorrente da modalidade virtual com que foi implantado.

Palavras-chave: ensino explícito; mapeamento espacial; Libras.

\begin{abstract}
Explicit teaching, according to Alves (2004), Gauthier (2014) and Rodrigues and Preuss (2018), is a pedagogical facility for the acquisition of L2 linguistic elements. For Silva (2018) the performance in Brazilian Sign Language (Libras) can be examined from the use of spatial mapping which is constituted by elements of nominal referencing, morphosyntactic production and referencing through the body. The present study aimed to investigate the effect of explicit teaching on performance in Libras as L2. The action research was characterized by the intervention with two groups of Libras apprentices of intermediate level, in one of which there was explicit teaching of spatial mapping. Participants performed the pre and post-test, which consisted of signaling a narrative. The account presented reports the data of two participants from each class. The results show that there was no effect of the explicit instruction in the use of nominal referencing and referencing through the body. Regarding the morphosyntactic production, there was not enough evidence to confirm the improvement in performance. In general, we did not observe the effect of explicit teaching on performance in Libras as L2, which can be partially explained by the lack of interaction resulting from the virtual modality with which it was implemented.

Keywords: explicit teaching; spatial mapping; Libras.
\end{abstract}

\section{INTRODUÇÃO}

Quando observamos uma sala de aula de L2, podemos constatar que a instrução explícita é um dos principais meios utilizados pelo professor em sua tarefa de ensinar a língua (ALVES, ZIMMER, 2005). Porém, será que essa prática pedagógica pode ser considerada a causa do desempenho satisfatório na língua-alvo? Ou então, é possível que a comunicação efetiva obtida pelos aprendizes seja efeito desse modo de instrução? Se a discussão sobre a relação causa-efeito nos processos de ensino de L2 oral é profícua à promoção de melhoria da aprendizagem, penso que para área que se dedica à Libras o tema seja ainda mais caro, haja vista que estudos voltados à prática pedagógica para o seu ensino como L2 são escassos no Brasil (SILVA, 2020).

Uma ferramenta pedagógica interessante, já anuncia a Linguística Contrastiva, é aquela que considera que as diferenças linguísticas entre a língua materna do aprendiz e a L2 em estudo costumam provocar dificuldades à aprendizagem (ANDRADE, 2014). Tal consideração, segundo pressupostos do ensino explícito, precisa motivar a busca pela exposição das formas distintas de modo a trazer consciência sobre elas. Ao que parece, no caso de ouvintes falantes de língua portuguesa como L1 que são aprendizes de Libras como L2 as dificuldades são decorrentes do fato de que as línguas em questão são de modalidades distintas (PICHLER $;$ KOULIDOBROVA, 2015). Devido a isso, os aprendizes precisam lidar com aspectos que não são usados nas línguas orais, mas podem interferir em seu

\footnotetext{
* Universidade Federal do Paraná (UFPR), Curitiba, PR, Brasil. lidiaufpr@gmail.com

Orcid https://orcid.org/0000-0002-1722-1753
} 
desempenho linguístico e comunicativo, tais como os elementos do Mapeamento Espacial: referenciação nominal, produção morfossintática e referenciação por meio do corpo.

Em vista de tal situação, esta pesquisa teve como objetivo geral investigar o efeito do ensino explícito no desempenho em Libras como L2. E tendo a hipótese de que o experimento gerasse grande efeito no desempenho de ouvintes sinalizantes de Libras como L2, foram definidas as seguintes perguntas norteadoras:

1. A instrução explícita da referenciação nominal da Libras causa grande efeito no desempenho em L2?

2. O ensino explícito da produção morfossintática ocasiona grande efeito no desempenho em Libras como L2?

3. O ensino explícito da referenciação por meio do corpo causa grande efeito no desempenho sinalizado de aprendizes de Libras?

A fim de responder essas questões, a pesquisa-ação desenhada, de caráter intervencionista, teve foco em aprendizes de Libras como L2, os quais produziram narrativas antes e depois da intervenção. Na análise do efeito, o uso da referenciação nominal, da produção morfossintática e da referenciação por meio do corpo foi avaliado no desempenho de quatro aprendizes, sendo duas integrantes do grupo controle (GC) e duas do grupo experimental (GE).

Este artigo está organizado em quatro seções. Inicialmente, exponho o referencial teórico que norteou o estudo. Posteriormente, descrevo a metodologia e, depois, apresento e discuto os resultados. Finalmente, trago algumas conclusões.

\section{REFERENCIAL TEÓRICO}

Neste referencial teórico, apresento as bases teórico-metodológicas da instrução explícita e um exemplo contrastivo entre português e Libras, através do qual se pode verificar a função, a importância e a dificuldade do uso do Mapeamento Espacial, que foi a forma saliente no ensino e na aferição do desempenho das aprendizes de Libras.

\subsection{A instrução explícita em Libras como L2}

Gauthier (2014, p. 4) elucida que as bases teóricas que sustentam o ensino explícito advêm da psicologia cognitiva, para a qual "a aprendizagem está intrinsecamente ligada à função de memória em geral, responsável pela construção, organização, codificação e recuperação do conhecimento". Segundo essa visão, a mente, assim como um computador, tem limite de processamento das informações. A compreensão é de que a arquitetura cognitiva é composta pela memória de trabalho e pela memória de longo prazo, consideradas pela teoria da carga cognitiva. Essa teoria

considera que existem dois processos, cuja função principal é permitir que a memória de trabalho, cujas capacidades são limitadas, processe grandes conjuntos de informações e melhore a aprendizagem [...]. O primeiro processo é a aquisição de padrões; o segundo, a automação deles. A teoria da carga cognitiva enfatiza a importância da automação que gradualmente permite que o indivíduo execute tarefas mais complexas, sem exceder a capacidade da memória de trabalho, uma vez que os padrões adquiridos podem processar uma grande quantidade de informações, como se fosse uma única unidade significativa ou um bloco ou um pedaço (GAUTHIER, 2014, p. 6).

De acordo com Rodrigues e Preuss (2018), no seio dessa proposta teórica também se discute que a distinção entre a instrução explícita e a implícita é dada pelo tipo de conhecimento aprendido pelo aluno, sendo que

o conhecimento explícito é aprendido, controlado e verbalizável, o que não significa que se refira a um conhecimento metalinguístico. Ademais, esse conhecimento permite o acesso à consciência. O conhecimento implícito, por sua vez, é mais intuitivo e adquirido de forma incidental, manifesta-se através do uso, de modo automático e não-verbalizável, trata-se de um conhecimento não consciente (RODRIGUES; PREUSS, 2018, p. 217).

A questão de interface entre um e outro conhecimento é motivo de bastante debate na área e tem gerado produção de hipóteses teóricas que defendem a conversão ou não de um conhecimento em outro (RODRIGUES, PREUSS, 2018).

A respeito das características práticas do ensino explícito, baseando-se em Rosenshine, Gauthier (2014, p. 7) informa que suas etapas são estruturadas e fortemente integradas e que isso visa evitar a sobrecarga cognitiva do aluno. Alega que é um método sistemático e apropriado para aprendizagem de diversas disciplinas, para alunos com perfis 
variados e que se afasta do ensino tradicional, já que nesse "o professor incentiva a transmissão do saber mediante um monólogo, enquanto no ensino explícito, o professor dialoga constantemente com os alunos". Quanto a isso, Rodrigues e Preuss (2018) afirmam que a instrução explícita assenta-se na abordagem comunicativa, pois visa tanto ensinar aspectos estruturais quanto abranger elementos do significado.

Como possibilidade pedagógica, a intervenção explícita é caracterizada pelo direcionamento "da atenção do aprendiz, de forma explícita, para diferentes aspectos [linguísticos e pragmáticos] do input" (RODRIGUES, PREUSS, 2018, p. 218). Esses referidos aspectos, destacam as pesquisadoras, não são ensinados "de modo descontextualizado", mas sim de forma comunicativa e com a participação ativa do aprendiz. Essa prática pedagógica de caráter explícito, segundo Alves (2004), pode ser conduzida pelo método indutivo (aquele que possibilita aos aprendizes descobrirem por eles mesmos a regra da forma-alvo) ou pelo método dedutivo (aquele em que o detalhe linguístico é fornecido pelo professor), sendo que o primeiro parece ser mais motivante e desafiador do que o segundo. As estratégias de instrução explícita que "foram validadas por evidências" e que são as "principais condições de um ensino eficaz", de acordo com Gauthier (2014, p. 2), são as resumidas a seguir:

1. Fase da preparação: é aquela em que o professor exprime com precisão os objetivos de aprendizagem, identifica as principais ideias, determina os conhecimentos prévios que os alunos precisam ter, integra de maneira estratégica vários tipos de conhecimento, planeja os dispositivos de sustentação da aprendizagem, planeja a revisão e verifica o alinhamento curricular.

2. Fase de interação com os alunos: é aquela em que o professor verifica as tarefas dadas no dia anterior, inicia, conduz e termina a aula. Para a condução da aula, o autor sugere as seguintes estratégias:

2.1 Modelagem - A introdução da aula é feita de maneira tão clara que os alunos conseguem perceber o que será aprendido e com qual objetivo. Nota também o objetivo da aprendizagem e os passos a serem percorridos ao longo do processo.

2.2 Prática guiada - Por meio de perguntas dirigidas às equipes, o professor conduz a interação, verifica a compreensão e dá suporte quando necessário. À medida que percebe progresso da turma, vai, gradativamente, suprimindo o apoio.

2.3 Prática independente - Uma vez que nessa parte o professor oferece exercícios de natureza similar aos da prática guiada, os alunos terão condições de realizá-los de forma autônoma.

1. Fase da consolidação: é aquela em que o professor passa tarefas para casa e realiza revisões semanais e mensais.

A respeito da condução da aula, convém observar que Alves (2004, p. 57) aponta que as atividades podem ser "desde aquelas [...] totalmente controladas até as que proporcionam a produção livre de frases contendo a estrutura alvo". Ainda, afirma que os aprendizes precisam

de tempo para integrar as novas estruturas aos seus sistemas de interlíngua, [e] deve-se considerar que, se o foco da prática for uma estrutura que o aprendiz ainda não está pronto para adquirir, tal trabalho provavelmente não será capaz de ter seus efeitos sentidos (ALVES, 2004, p. 57).

Além disso, o autor é adepto à ideia de que a prática pedagógica pode ser complementada com o suporte do feedback negativo para assimilação de novos elementos linguísticos.

Vários estudos envolvendo línguas orais têm demonstrado os benefícios e os efeitos duradouros para grupos que recebem a instrução explícita (ALVES, 2004; ALVES; ZIMMER, 2005; GAUTHIER, 2014) em comparação com estudantes que não têm acesso a esse tipo de intervenção. Assinalam, ainda, que os participantes que recebem mais instrução obtêm resultados melhores do que os que recebem menos instrução (LIMA JúNIOR, 2010).

Para tanto, a defesa do ensino explícito como ferramenta pedagógica eficiente tem apresentado, principal e sinteticamente, as seguintes argumentações (Quadro 1): 
Quadro 1. Os benefícios da instrução explícita

Em uma perspectiva cognitiva, o ensino explícito:

- Facilita o processamento cognitivo do input da L2: a instrução explícita contribui com o processamento do input da L2, uma vez que chama a atenção para detalhes linguísticos que o aprendiz não estava comprometido em notar e, assim, o torna mais atento às respectivas realizações na língua;

- Mostra grande pertinência para a produção do output da L2: devido ao fato de o aprendiz passar a notar as formas-alvos, torna-se apto a produzi-las na língua;

- Auxilia a formação de conbecimento explícito e implícito: esse tipo de instrução conduz à formação do conhecimento explícito e implícito, que, por sua vez, favorecem o automonitoramento do aprendiz;

- Simplifica a aprendizagem: baseando-se no fato de que a memória de trabalho tem capacidade limitada e rapidamente torna-se sobrecarregada, o oferecimento do conteúdo por etapas, organizado com boas estratégias (incluindo modelagem, prática orientada e prática independente) facilita a aprendizagem.

Fonte: Elaborado pela autora com base em Alves (2004), Alves e Zimmer (2005) e Gauthier (2014)

Apesar de a instrução explícita ser uma temática largamente debatida ${ }^{1}$ nos estudos relacionados à aquisição de uma L2 oral, sua abordagem é inédita na área dedicada à aquisição de L2 sinalizada, sendo a pesquisa de Geer e Keane (2018) a exceção. Nela, os autores trabalharam com 18 estudantes universitários em seu terceiro semestre de estudo da língua americana de sinais e os dividiram em dois grupos: um recebeu treinamento fonético explícito e o outro, treinamento implícito. Seus dados revelam que, apesar da curta exposição à instrução, houve melhoria significativa do pré-teste para o pós-teste no caso dos alunos que receberam o treinamento.

\subsection{0 uso do mapeamento espacial (ME) em Libras}

Para início de discussão, apresento o fragmento (I), que contém elementos referenciais da língua portuguesa, e o (II), que contém a transcrição da produção da mesma porção textual em Libras²:

(I) Um homem trabalhava pegando peras em uma árvore e as colocava no seu bolso. Uma fruta caiu, e ele desceu da árvore para pegá-la. Havia três cestos para colocar as peras. Dois estavam completamente cheios, e um estava vazio.

(II) ${ }^{3}$ HOMEM TRABALHAR ÁRVORE < gesto para objeto redondo $>$ QUE PERA TRABALHAR PEGAR ${ }_{\text {objeto }}$ redondo da árvore COLOCAR $_{\text {objeto redondo no bolso }}$ CAIR 1 PERA CAIR HOMEM DESCER < gesto para objeto redondo $>$ $3<$ gesto para objeto redondo $><$ gesto para objeto redondo $><$ gesto para objeto redondo $>2$ CHEI@, CHEI@VAZI@4

Explicando a notação da realização em Libras, destaco que as palavras transcritas em letras maiúsculas correspondem aos itens lexicais, a marcação ? equivale a demonstração da expressão interrogativa, e as descrições entre $<>$ correspondem a expressões não equivalentes em português e que foram realizadas de duas formas diferentes e compreensíveis pelo contexto, conforme demonstra a Figura 1:

1. Baseando-se em Norris e Ortega (2000), Lima Júnior (2010) aponta que, no período de 1980-1998, 250 estudos foram publicados sobre o tema e apontam que a instrução focalizada de L2 resulta em ganhos superiores (e duráveis) em relação aos da instrução implícita. Dentre os estudos que tomamos conhecimento apenas o de Rodrigues e Preuss (2018) destaca evidências negativas para os efeitos da instrução explícita.

2. Extraída do Corpus Libras da Universidade Federal de Santa Catarina (UFSC, 2014), de domínio público, e disponibilizada no YouTube para fins desta pesquisa https://www.youtube.com/watch?v=GpX-Z0R_wic.

3. Transcrição simplificada feita pelo sistema de notação por palavras de Ferreira-Brito (1995).

4. De acordo com esse sistema de notação por palavras, o uso do arroba (@) em Libras indica a ausência da marca de gênero, pois os sinais não apresentam marcas desse tipo. 


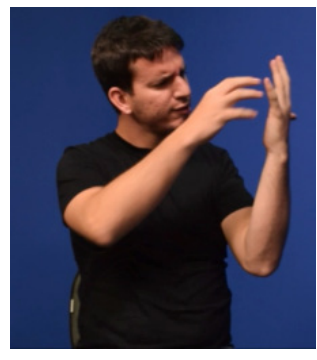

(A)

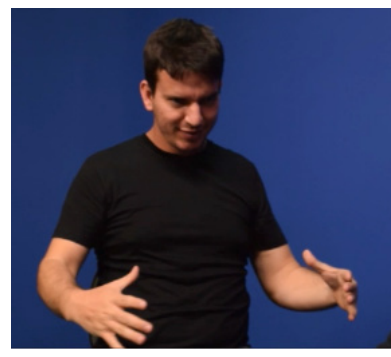

(B)

Figura 1. Gesto para objeto redondo

Fonte: UFSC (2014)

A foto em (A) ilustra a referência à pera, e o sinal demonstrado em (B) relaciona-se a um dos cestos. Esse gesto de (B), que faz menção ao objeto redondo e grande, foi realizado três vezes em três pontos distintos na frente do corpo do sinalizante, em ponto baixo do espaço, de modo a transmitir a ideia de quantidade dos objetos. Para expressar a ideia de que "dois estavam completamente cheios e um estava vazio", o sinalizante realizou o apontamento para os locais em que os dois primeiros < gesto para objeto redondo $>$ foram feitos e realizou o item lexical CHEI@. Apontou para o local em que o terceiro < gesto para objeto redondo > foi sinalizado e realizou o item lexical VAZI@. Todas as ocorrências foram acompanhadas dos componentes não manuais: inclinação da cabeça, direção do olhar (que deixou de estar na direção do interlocutor e foi direcionado para o local específico no espaço) e dos ombros, bochechas infladas para os primeiros < gesto para objeto redondo > e sugadas para o terceiro.

As palavras subscritas referem-se à interpretação contextual daquela dada gestualidade. Por exemplo, em PEGAR observa-se que o sinalizante reproduziu, através do corpo, a ação de colher as frutas. Ao reproduzir essa ação, a configuração da sua mão manteve a referência ao ato de segurar um objeto redondo e o local inicial do sinal se deu a partir do contato com a mão passiva que estava realizando o sinal de ÁRVORE. Por meio do movimento realizado com a mão, transmitiu a informação do local em que as peras foram guardadas (no bolso, no caso) como em COLOCAR

O sinal de DESCER foi realizado com seu respectivo frame semântico, ou seja, com a manutenção da iconicidade que remeteu ao movimento que uma pessoa realiza com as pernas ao descer de uma árvore. A forma da sua mão também representou a personificação das pernas. Pela possibilidade de produção simultânea de dois sinais, o sinalizante manteve a mão que realizou o sinal de ÁRVORE ativa e demonstrou o local em que a ação de DESCER ocorreu. Essa realização não só demonstrou a afinidade semântica entre sujeito e objeto, como também apresentou a descrição locativa da cena. Esse é um tipo de verbo que expressa as informações topográficas das pessoas em relação aos objetos; por meio do deslocamento da mão, demarca-se a relação entre o homem e a árvore e a árvore e os cestos.

A descrição apresentada evidencia o uso dos elementos que compõem o mapeamento espacial da Libras, uma vez que ele é responsável pelas diferentes formas de referenciar pessoas e objetos ao longo da sinalização. Resumidamente, para dizer a sentença (II) faz-se uso dos elementos elencados no Quadro 2:

Quadro 2. 0 uso do mapeamento espacial em Libras ${ }^{5}$

\begin{tabular}{|c|c|c|}
\hline \multicolumn{3}{|c|}{ Elementos do $\mathrm{ME}^{5}$} \\
\hline \multirow{7}{*}{$\begin{array}{l}\text { Pequena } \\
\text { escala }\end{array}$} & \multirow{4}{*}{ Referenciação nominal } & Relação contrastiva e afinidade semântica \\
\hline & & Apontamento \\
\hline & & Componentes não manuais \\
\hline & & Modificação da localização prototípica do sinal e criação de imagens topográficas \\
\hline & \multirow{3}{*}{ Produção morfossintática } & Concordância verbal (com sujeito e objeto da frase) \\
\hline & & Verbo espacial (com a correta configuração de mão) \\
\hline & & Verbo manual (com iconicidade, gestualidade e representatividade) \\
\hline
\end{tabular}

5. Para uma leitura mais aprofundada a respeito do ME em Libras, consultar Silva (2018). 


\begin{tabular}{|c|c|c|}
\hline \multirow{3}{*}{$\begin{array}{l}\text { Larga } \\
\text { escala }\end{array}$} & \multirow{3}{*}{$\begin{array}{l}\text { Referenciação por meio } \\
\text { do corpo }\end{array}$} & Uso do corpo para demonstrar as ações do personagem \\
\hline & & $\begin{array}{l}\text { Uso do corpo para demonstrar características físicas, emoções e pensamentos do } \\
\text { personagem }\end{array}$ \\
\hline & & Uso do corpo para demonstrar conversas entre os personagens \\
\hline
\end{tabular}

Fonte: Elaboração própria

Essa amostra do contraste linguístico ${ }^{6}$ entre a língua materna do aprendiz e a Libras, que é sua língua-alvo, deriva de uma corrente que, conforme explica Rasaba Fernández (2011, p. 4), é oriunda dos anos 1940 e "procura determinar as diferenças e similitudes entre as duas línguas e, assim, prever as possíveis áreas nas quais os estudantes terão dificuldades no processo de aprendizagem da língua estrangeira ${ }^{7 \prime}$.

Assim, entendo que o Mapeamento Espacial, além de um importante constituinte das línguas sinalizadas, é motivador de dificuldade para aprendizagem pelos aprendizes em virtude da distância interlinguística com o português. Para Winston (1995), esse é um recurso extremamente importante na construção da mensagem, que leva à compreensão e serve para a construção de discursos coerentes. Uma evidência empírica de que a ausência do mapeamento espacial repercute na falta de clareza é constatada no estudo seminal de Silva e Silva (2019), que apresenta a avaliação de juízes surdos quanto à produção de verbos manuais de aprendizes de L2. As autoras relatam que a omissão de representatividade e de iconicidade na sinalização dos ouvintes é negativamente avaliada pelos surdos.

Além disso, de acordo com Silva (2018), o uso do mapeamento espacial por aprendizes de L2 evita a produção de mensagens com sentido comprometido, pois mesmo que sejam inteligíveis por interlocutores surdos podem ser consideradas de desempenho pouco satisfatório. Como exemplo apresento a transcrição de uma produção em Libras como L2 extraída dos dados da pesquisa:

\section{(III) ÁRVORE PESSOA PEGAR MAÇÃ PERA PEGAR PEGAR CAIR DESCER LUGAR LUGAR LUGAR INDEX < gesto para objeto redondo > PERA MAÇÃ INDEX DEPENDE INDEX NADA}

Os problemas desse fragmento não são manifestados pelo uso de itens lexicais distintos de (II), mas pelo uso comprometido dos elementos do mapeamento espacial (Quadro 2). Na imagem (A) da Figura 2, observa-se que a configuração de mão para realização do sinal de ÁRVORE está diferente da usual (demonstrada em B) e na imagem (C) nota-se uso comprometido do < gesto para objeto redondo>, já que deixou de demostrar o volume como o ilustrado em (D). Tais realizações prejudicam a criação de imagens topográficas.

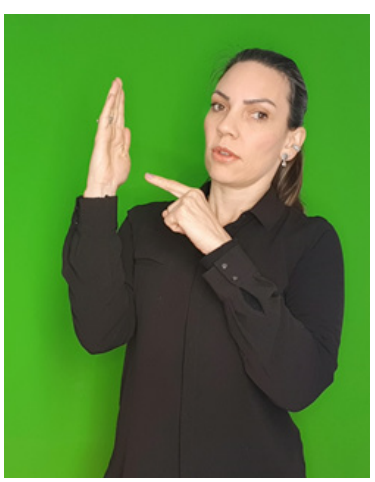

(A)

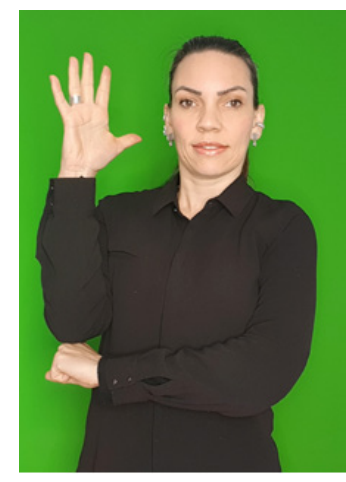

(B)

6. Poucos são os estudos linguísticos sobre referenciação em Libras, e nenhum apresenta a comparação explícita com a língua portuguesa. Esse é um interessante e necessário tema de pesquisa, uma vez que as expressividades e histórias desses idiomas são muito distintas e a modalidade, não compartilhada, certamente influencia ainda mais o funcionamento linguístico. Em caso de estudo contrastivo, a grande variação no desempenho da comunidade surda não deve deixar de ser considerada uma vez que reflete aspectos sociais, políticos e culturais que envolvem os falantes surdos.

7. Para fins deste estudo, as expressões língua estrangeira e segunda língua são indistintas. 


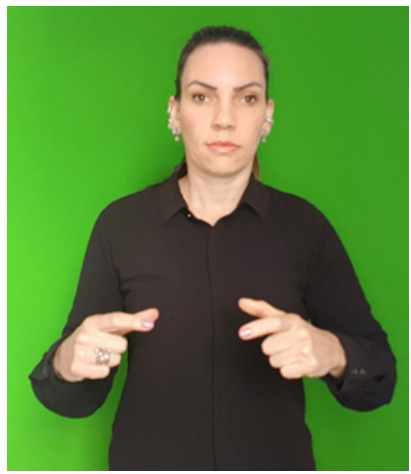

(C)

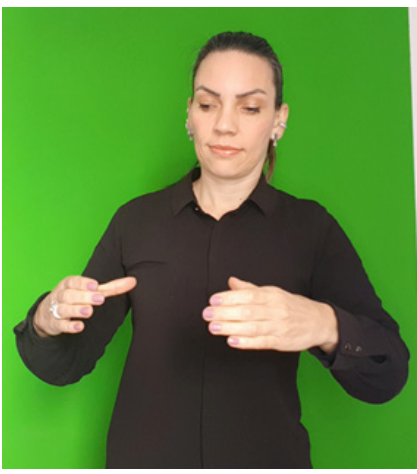

(D)

Figura $2^{8}$. Mapeamento espacial em Libras como L2: criação de imagens topográficas Fonte: Dados da pesquisa

Pela imagem (A) da Figura 3 pode-se notar a dificuldade da aprendiz na realização do verbo manual PEGAR ${ }_{\text {objeto }}$ redondo da árvore já que falta a iconicidade (imagem B) que transmite a ideia de que se trata de um objeto redondo sendo pego.

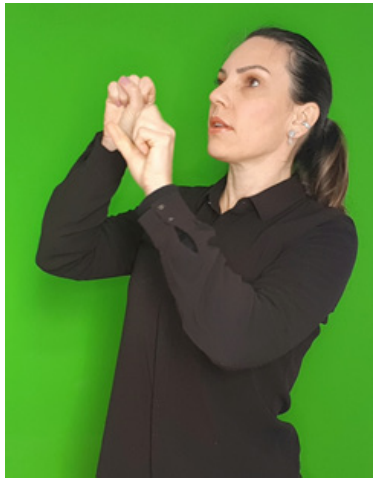

(A)

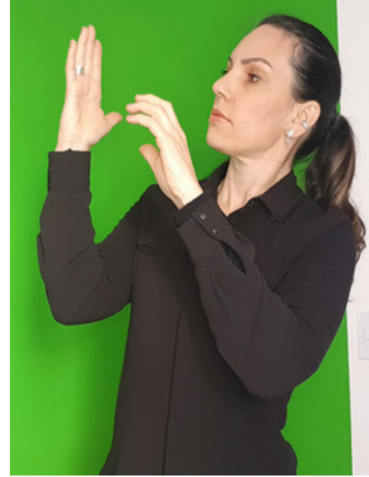

(B)

Figura 3. Mapeamento espacial em Libras como L2: verbo manual Fonte: Dados da pesquisa

Essa idiossincrasia manifesta que a aprendiz necessita avançar no uso dos verbos manuais, que são importantes elementos do Mapeamento Espacial.

Esses exemplos reforçam o que apontam Silva (2018) e Winston (1995) a respeito da dificuldade para a aprendizagem do mapeamento espacial no caso de ouvintes e, portanto, merecem atenção por parte do professor.

\section{METODOLOGIA}

Para alcançar o objetivo de investigar os efeitos do ensino explícito no desempenho em Libras como L2, foi conduzida uma pesquisa-ação de caráter intervencionista. Nesse tipo de estudo, o pesquisador percorre as etapas de

1. identificação de um problema, de uma situação que exige mudança,

2. coleta de dados para análise,

3. formação de uma hipótese para planejamento da intervenção;

4. intervenção;

5. avaliação dos efeitos da intervenção;

6. disseminação.

LIMA JÚNIOR (2010, p. 755)

8. Todos os dados apresentados são provenientes da pesquisa, mas estão sendo reproduzidos pela autora do artigo - exatamente da forma realizada pelas participantes - para preservar suas identidades. 
Como as etapas 1 e 3 já foram apresentadas na Introdução, e a 6 se concretiza com o relato ora exposto, passo à demonstração da coleta de dados (2) e da intervenção realizada (4). Na próxima seção, apresento os resultados da intervenção e a avaliação dos seus efeitos (5).

\subsection{A coleta de dados}

O Núcleo de Ensino de Libras (NEL) é vinculado ao Curso de Letras Libras da Universidade Federal do Paraná (UFPR), atua em atividades de extensão relacionadas ao ensino dos níveis básico, intermediário e avançado da Libras e, de acordo com o projeto inicial da pesquisa, seria o local da coleta de dados. Entretanto, em 2020, por conta da pandemia do coronavírus e das medidas de distanciamento social, o curso de extensão não ocorreu; então, os instrumentos da coleta foram adaptados. Para isso, os cursistas que em 2019 realizaram o nível intermediário foram convidados a participar de um curso, chamado de "Pré-avançado", que aconteceria pelo WhatsApp e teria duração de dois meses. Todos foram informados de que o curso seria ministrado devido à pesquisa e que, portanto, disponibilizariam seus dados à pesquisadora. Os 20 participantes que concordaram assinaram o Termo de Consentimento Livre e Esclarecido (TCLE) ${ }^{9}$.

Os voluntários foram então divididos em dois grupos. O Grupo Experimental foi composto pelos 10 primeiros alunos (organizados pelo critério da ordem alfabética dos seus nomes) e recebeu a intervenção sem saber exatamente o propósito do estudo. Já o Grupo Controle, composto por 10 alunos, teve aulas, também pelo WhatsApp, com uma professora surda que conduziu os mesmos conteúdos do Mapeamento Espacial, só que com abordagem diferente da instrução explícita. O relato que segue diz respeito à análise do efeito do ensino explícito no desempenho de quatro ${ }^{10}$ aprendizes, a saber: Lana, Carmem, Rosa e Marta ${ }^{11}$. As primeiras fizeram parte do Grupo Experimental e as últimas do Grupo Controle (Quadro 3):

Quadro 3. Os participantes da pesquisa

\begin{tabular}{|c|c|c|c|c|}
\hline TURMA & ALUNOS & PROFESSORA & INTERVENÇÃO & DUPLA ANALISADA \\
\hline $\begin{array}{c}\text { Grupo Experimental } \\
\text { (Pré-avançado A) }\end{array}$ & 10 & Ouvinte & Sim & $\begin{array}{c}\text { Lana e Carmem (Dupla } \\
\text { Experimental) }\end{array}$ \\
\hline $\begin{array}{c}\text { Grupo Controle } \\
\text { (Pré-avançado B) }\end{array}$ & 10 & Surda & Não & Rosa e Marta (Dupla Controle) \\
\hline
\end{tabular}

Fonte: Elaboração própria

Todos os participantes do Grupo Experimental e do Grupo Controle realizaram o pré-teste, que consistiu em assistir à história da pera' ${ }^{12}$ (quantas vezes quisessem) e gravar-se contando-a em Libras (quantas vezes achem necessárias). Esse material de estímulo foi escolhido por ser utilizado em várias pesquisas linguísticas; trata-se de um filme de aproximadamente 6 minutos sem linguagem verbal, contendo imagens, sons naturais do cenário (canto de pássaros) e barulhos próprios às ações apresentadas. O pós-teste seguiu o mesmo protocolo do pré-teste e foi gravado após o término da intervenção por cinco participantes do Grupo Experimental e duas participantes do Grupo Controle. Todos os vídeos foram enviados pelo WhatsApp para a pesquisadora.

\subsection{0 protocolo de intervenção: o ensino explícito do Mapeamento Espacial}

A intervenção durou dois meses (de 25 de agosto a 25 de outubro de 2020) e foi conduzida pela pesquisadora através do aplicativo WhatsApp. O planejamento proposto para o trabalho com cada um dos três elementos do mapeamento espacial (referenciação nominal, produção morfossintática e referenciação por meio do corpo) seguiu

9. Pesquisa aprovada pelo CEP sob n ${ }^{\circ}$ CAAE 24828419.4.0000.0102.

10. Esse baixo número é devido ao fato de que em ambos os grupos (experimental e controle) houve desistência de alguns participantes. Apenas duas participantes do Grupo Controle realizaram o pós-teste.

11. Foram utilizados nomes fictícios para preservar a identidade das participantes.

12. As imagens mostram um homem colhendo peras e que não vê a presença de um jovem puxando um bode, muito menos um menino de bicicleta que rouba uma de suas cestas cheias de peras. O menino distrai-se ao ver uma menina, bate sua bicicleta em uma pedra, derruba as peras e cai. Três adolescentes ajudam-no, e cada um deles recebe uma pera como recompensa. Ao passarem pelo senhor que havia descido da árvore e percebido a falta da cesta, são olhados com desconfiança. 
o modelo de Gauthier (2014), que destaca que a condução da aula inclui: i) modelagem, ii) prática orientada e iii) prática independente.

A primeira modelagem ocorreu através de um vídeo gravado em Libras e enviado ao grupo do WhatsApp pela pesquisadora, com explicações sobre a referenciação nominal. Nessa parte, foram fornecidos exemplos de como sentenças em português poderiam ser adequadamente produzidas em Libras com a aplicação da relação contrastiva, da afinidade semântica, do apontamento, dos componentes não manuais, da modificação da localização prototípica do sinal e da criação de imagens topográficas. Após isso, um vídeo sobre quarentena (HUMORISTA ZAIRE, 2020) com a sinalização de um surdo foi oferecido para que os aprendizes pudessem realizar as tarefas solicitadas. A escolha desse vídeo se deu devido ao fato de que o Grupo Controle estava realizando atividades relacionadas à temática do coronavírus, portanto avaliou-se como oportuno o oferecimento do mesmo input aos participantes do Grupo Experimental.

Posteriormente, a pesquisadora passou à prática orientada, pedindo que os participantes se organizassem em grupos para proceder à identificação dos elementos da referenciação nominal no vídeo a que assistiram. A pesquisadora estava presente durante a videochamada realizada pelos grupos e orientava à prática sempre que era necessário.

A prática independente foi conduzida por meio do oferecimento de frases em português que deveriam ser produzidas em Libras, individualmente, gravadas em vídeo e enviadas pelo WhatsApp. Conforme demonstrado na Figura 4, houve feedback negativo a respeito do uso do elemento em estudo.
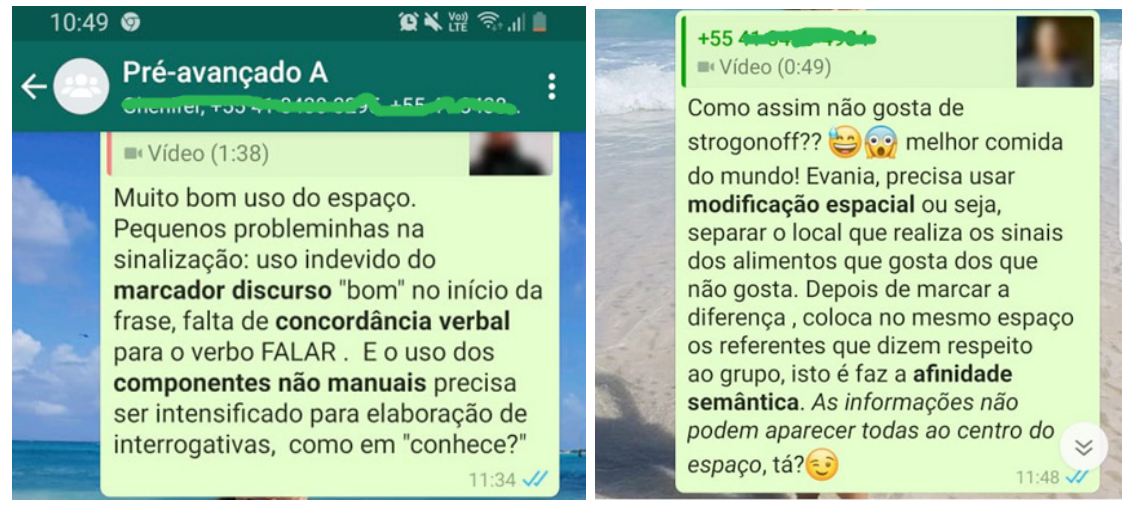

Figura 4. Prática independente e feedback do GE

Fonte: Dados da pesquisa

A segunda modelagem ocorreu da mesma forma que a primeira. A pesquisadora ofereceu um vídeo em Libras com explicação explícita a respeito da produção morfossintática. Os exemplos no Quadro 4 foram apresentados para elucidar o funcionamento dos verbos de concordância, espaciais e manuais da Libras:

Quadro 4. Exemplos de modelagem dos diferentes tipos de verbos da Libras ${ }^{13}$

a) Eu já aconselhei toda minha família sobre os perigos do coronavírus. (Exemplo de uso de um verbo com concordância)

b) Eu marquei de viajar a Londrina, mas devido à pandemia precisei cancelar a viagem. (Exemplo de uso de verbo espacial)

c) Durante a quarentena não cortei os cabelos. (Exemplo de uso de um verbo manual)

Fonte: Dados da pesquisa

Posteriormente, um vídeo sobre covid-19 (INES DDHCT, 2020) foi oferecido aos participantes para que, na sequência, pudessem realizar a prática orientada. Novamente, a dinâmica ocorreu em grupos, que deveriam proceder à extração de um exemplo de cada verbo da sinalização assistida.

Na prática independente, os aprendizes produziram três frases (uma para cada tipo de verbo) a respeito do conteúdo do vídeo, as quais foram gravadas e enviadas ao grupo e receberam feedback negativo.

13. O verbo simples (Eu não gosto do coronavírus) foi utilizado como introdução da modelagem. 
A terceira e última modelagem se deu com a explanação da pesquisadora a respeito da referenciação por meio do corpo e com oferecimento do input "saber mais coronavírus" (TV INES, 2020). Após assistirem ao vídeo, os aprendizes realizaram a prática orientada que se deu em grupos por videochamada no WhatsApp.

$\mathrm{Na}$ prática independente, os aprendizes produziram quatro frases sobre o vídeo assistido e suas produções receberam feedback negativo a respeito do uso da referenciação por meio do corpo.

Considerando a troca de mensagens no aplicativo, a extensão dos vídeos enviados, os feedbacks fornecidos, bem como as interações pelas videochamadas, a intervenção foi de 1 h30 de atividade por dia, em média.

\section{RESULTADOS: AVALIAÇÃO DOS EFEITOS DA INTERVENÇÃO}

A tabulação dos dados foi realizada no programa Excel de forma binária avaliando-se a realização (ou não) de cada elemento do ME durante as narrativas do pré- e do pós-teste. Em caso de identificação de produção, atribuiu-se o escore (1), que indicava acerto. Por sua vez, as omissões foram tratadas com o escore $(0)^{14}$. A seguir apresento o desempenho da Dupla Experimental e da Dupla Controle em cada elemento do Mapeamento Espacial.

\subsection{Referenciação nominal}

Para começar, apresento o Quadro 5, que contém o desempenho das participantes nos dois testes:

Quadro 5. Desempenho em relação à referenciação nominal nas participantes da Dupla Experimental e da Dupla Controle no préteste e no pós-teste

\begin{tabular}{|c|c|c|c|c|c|c|c|c|c|c|}
\hline \multirow{3}{*}{$x^{2}$} & & & \multicolumn{4}{|c|}{ Dupla Experimental } & \multicolumn{4}{|c|}{ Dupla Controle } \\
\hline & & ementos do ME & \multicolumn{2}{|c|}{$\begin{array}{l}\text { Desempenho } \\
\text { de Lana }\end{array}$} & \multicolumn{2}{|c|}{$\begin{array}{c}\text { Desempenho } \\
\text { de Carmem }\end{array}$} & \multicolumn{2}{|c|}{$\begin{array}{c}\text { Desempenho de } \\
\text { Rosa }\end{array}$} & \multicolumn{2}{|c|}{$\begin{array}{c}\text { Desempenho } \\
\text { de Marta }\end{array}$} \\
\hline & & & $\begin{array}{l}\text { Pré- } \\
\text {-teste }\end{array}$ & $\begin{array}{l}\text { Pós- } \\
\text {-teste }\end{array}$ & $\begin{array}{l}\text { Pré- } \\
\text {-teste }\end{array}$ & $\begin{array}{l}\text { Pós- } \\
\text {-teste }\end{array}$ & $\begin{array}{l}\text { Pré- } \\
\text {-teste }\end{array}$ & $\begin{array}{l}\text { Pós- } \\
\text {-teste }\end{array}$ & $\begin{array}{l}\text { Pré- } \\
\text {-teste }\end{array}$ & $\begin{array}{l}\text { Pós- } \\
\text {-teste }\end{array}$ \\
\hline \multirow{4}{*}{$\begin{array}{l}\frac{\pi}{\tilde{J}} \\
\tilde{U} \\
\tilde{J} \\
\tilde{\Xi} \\
\tilde{J} \\
\tilde{D}\end{array}$} & \multirow{4}{*}{ 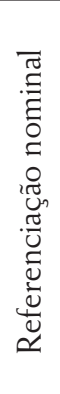 } & $\begin{array}{l}\text { Relação contrastiva e } \\
\text { afinidade semântica }\end{array}$ & 0 & 0 & 0 & 0 & 0 & 0 & 0 & 0 \\
\hline & & Apontamento & 1 & 1 & 1 & 1 & 0 & 0 & 0 & 0 \\
\hline & & Componentes não manuais & 0 & 0 & 1 & 1 & 1 & 1 & 1 & 1 \\
\hline & & $\begin{array}{l}\text { Modificação da localização } \\
\text { do sinal e criação de } \\
\text { imagens topográficas }\end{array}$ & 0 & 0 & 0 & 0 & 0 & 0 & 1 & 0 \\
\hline
\end{tabular}

Fonte: Elaboração própria

Pelos dados expostos, é possível perceber a semelhança no desempenho inicial das participantes da Dupla Experimental, com a diferença de que Carmem não apresentou erro na realização dos componentes não manuais, enquanto Lana sim, já que não mudou a direção do olhar, da cabeça e dos ombros - manteve-a somente para a câmera. A Dupla Controle também apresentou desempenho semelhante com relação a esse elemento, no pré-teste, com a exceção de que Marta não errou a criação de imagens topográficas. A análise intraduplas revelou exatamente o mesmo escore para o teste inicial.

Do pré-teste observa-se ainda que o elemento com que as participantes lidaram melhor foram os componentes não manuais, enquanto a relação contrastiva e a afinidade semântica foram as que mais geraram dificuldade. A esse respeito convém apontar que os componentes não manuais são recursos gestuais disponíveis no repertório comunicativo dos aprendizes e, normalmente, fazem parte dos conteúdos dos programas de ensino de Libras. Essas razões, acredito, levaram ao devido uso pelas duplas. A relação contrastiva e a afinidade semântica, por outro lado,

14. Em outros estudos (no prelo) de natureza descritiva, considero a reincidência de realização ou de ausência de um mesmo tipo de verbo na sinalização bem como estreito a caracterização de cada categoria verbal de modo que a inter-relação entre a produção morfossintática e a referenciação nominal mostra-se evidente. Para uma análise binária, entretanto, a falta de uso em um contexto necessário foi suficiente para aferir o escore (0). 
não são trabalhadas nos cursos de Libras ou, quando o são, aparecem de maneira muito tímida e não sistematizada. Haja vista essa deficiência pedagógica, constata-se em realidade regional que mesmo em aprendizes avançados do idioma (ou mesmo em profissionais tradutores e intérpretes de Libras) esse elemento é utilizado de forma bastante precária (aparecendo em frases curtas, mas não em discursos mais longos).

Sobre o pós-teste, os dados indicam uma pequena vantagem no desempenho da Dupla Experimental. Assim como no pré-teste, os componentes não manuais continuaram sendo os mais usados, mas a criação de imagens topográficas juntou-se aos elementos causadores de dificuldade no pós-teste. A criação de imagens topográficas, como mencionado anteriormente, depende da acurácia fonológica do sinalizante e, portanto, o domínio dos parâmetros linguísticos (principalmente a configuração de mão e movimento) parece ser um pré-requisito para sua produção (PICHLER; KOULIDOBROVA, 2015).

Apesar da pequena diferença notada no uso da modificação da localização do sinal e da criação de imagens topográficas no desempenho inicial e final de Marta (considerada não significativa neste estudo ${ }^{15}$ ), pode-se dizer que em relação à referenciação nominal os dados apontam que as duplas mantiveram os escores nos dois testes e que o elemento de maior dificuldade na relação nominal é o estabelecimento da relação contrastiva e da afinidade semântica durante a contação da narrativa.

Ora, se a instrução explícita parece que não surtiu nenhum efeito à Dupla Experimental e a instrução recebida pela Dupla Controle também não foi capaz de proporcionar avanço no seu desempenho, posso conjecturar que ou os erros de omissões apresentados estão fossilizados (DURÃO, 2004) ou então trata-se de estruturas que as aprendizes ainda não estão prontas para adquirir (ALVES, 2004).

Portanto, respondendo mais claramente à primeira pergunta de investigação, é possível afirmar que não houve efeito da instrução explícita da referenciação nominal da Libras no desempenho em L2.

\subsection{Produção morfossintática}

As realizações de erros e acertos da Dupla Experimental e da Dupla Controle estão demonstradas no Quadro 6:

Quadro 6. Desempenho em relação à produção morfossintática nas participantes da Dupla Experimental e da Dupla Controle no pré-teste e no pós-teste

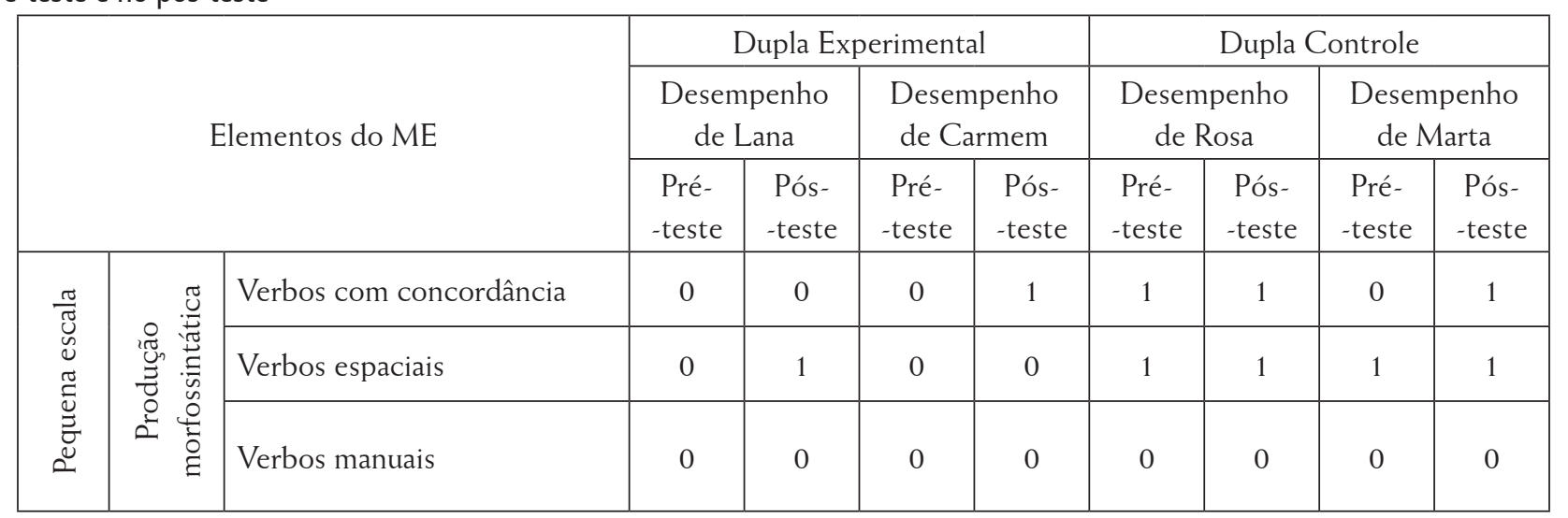

Fonte: Elaboração própria

A Dupla Controle teve um desempenho inicial melhor do que a Dupla Experimental e, no pré-teste, ambas as duplas produziram os verbos manuais de forma incorreta. Após as intervenções, o desempenho da Dupla Experimental foi melhor do que o da Dupla Controle, uma vez que Lana progrediu em relação ao uso de verbos espaciais e Carmem conseguiu produzir concordância verbal. Dados os ganhos de aprendizagem, convém ilustrá-los (Figura 5):

\footnotetext{
15. Se bem que, se essa manifestação fosse investigada com profundidade, poderia revelar se foi causada por "cansaço, lapsos de memória, fortes emoções, ansiedade, descuido" e, portanto, "não reflete o conhecimento do falante". (RABASA FERNÁNDEZ, 2011, p. 6). A própria "pressão" da tarefa repetida, a ser entregue em vídeo, é uma variável que pode ter causado estresse aos aprendizes, e isso pode ter ocasionado a supressão do elemento do ME.
} 


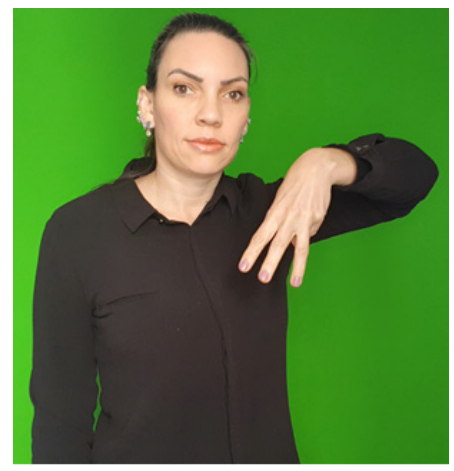

(A)

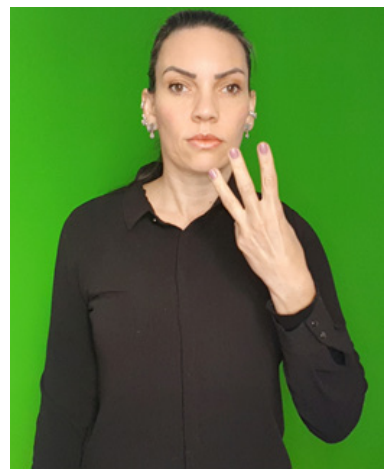

(B)

Figura 5. Uso de verbo espacial ANDAR pela participante Lana no pré-teste e no pós-teste Fonte: Dados da pesquisa

No pré-teste, Lana realizou o sinal de ANDAR para os três meninos com uma configuração de mão que remetia à quantidade de três personagens, entretanto os parâmetros fonológicos — orientação dos dedos para baixo e movimento para frente - realizados não são usuais em Libras. No pós-teste, conforme demonstrado na imagem (B) da Figura 5, ela usou a correta personificação das três pessoas e realizou o movimento adequado.

No pré-teste, Carmem sinalizou os itens lexicais AQUI (A) e TRÊS (B), da Figura 6, e depois demonstrou, claramente, que definiu três pontos como loci para referenciação dos < gesto para objeto redondo $>$. As sequências de imagens em $(\mathrm{C})$ retratam a correta distribuição dos sinais à frente do corpo da participante.

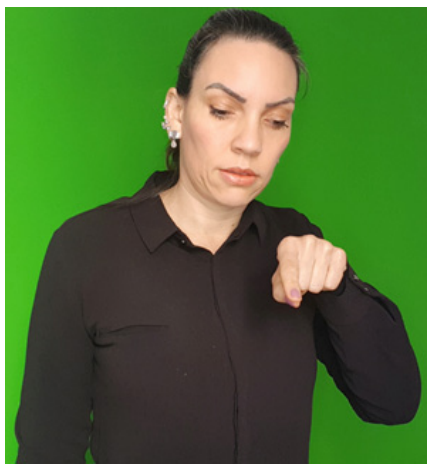

(A)
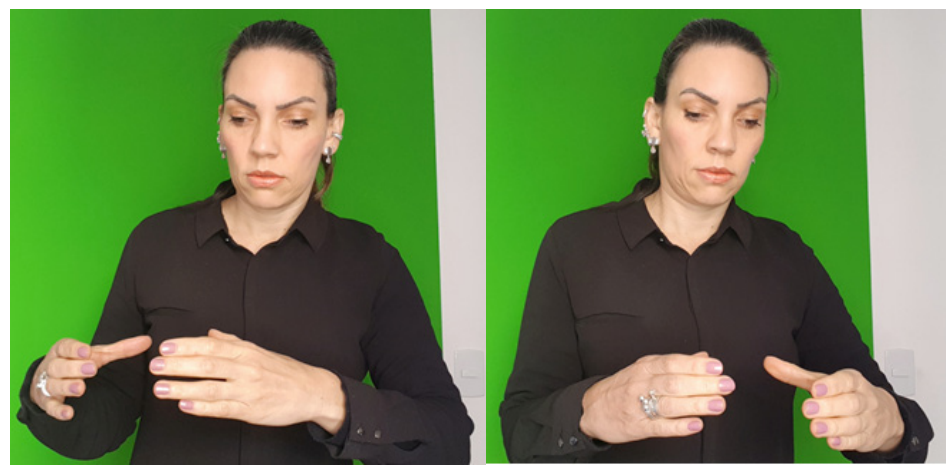

(C)

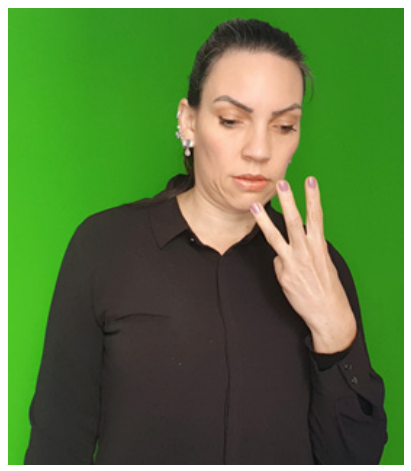

(B)

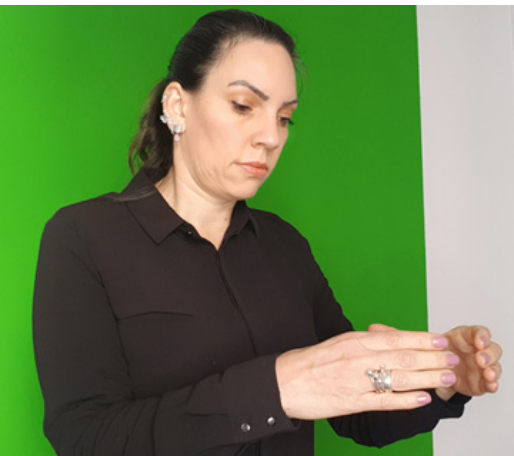

Figura 6. Produção da frase AQUI 3 CEST@ da participante do Grupo Experimental durante a realização do pré-teste Fonte: Dados da pesquisa

Após decorridas algumas elocuções, disse que o menino viu uma das cestas e a pegou. Ocorre que a aprendiz sinalizou o sinal de VER em direção a locais onde as cestas não haviam sido referenciadas. A incorreção ilustrada 
na Figura 7 demonstra a direção do olhar para três pontos altos no espaço, e não nos loci anteriormente definidos (Imagem C da Figura 6).

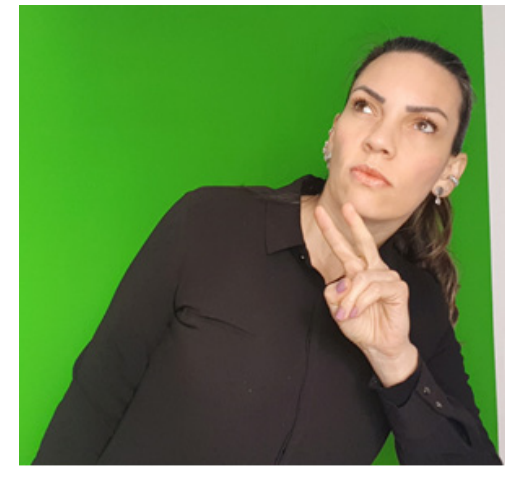

(A)

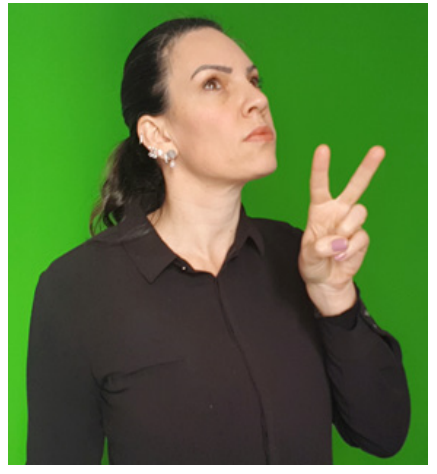

(B)

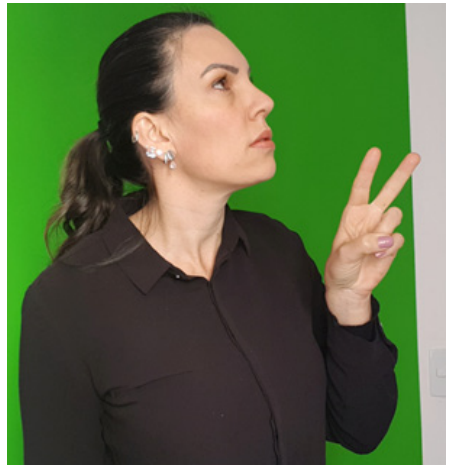

(C)

Figura 7. Pré-teste: omissão da concordância verbal na participante do Grupo Experimental Fonte: Dados da pesquisa

No pós-teste, Carmem novamente definiu pontos à frente do corpo para os cestos, mas dessa vez realizou corretamente o verbo VER nessas direções (Imagem C da Figura 6). $\mathrm{O}$ acerto da aprendiz está ilustrado na sequência de imagens da Figura 8:

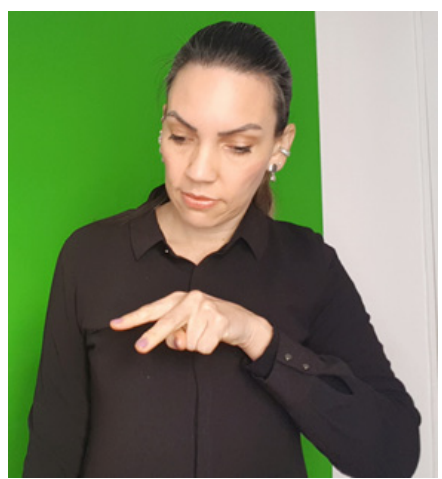

(A)

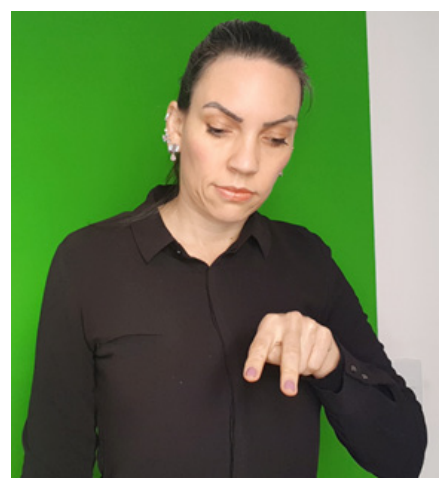

(B)

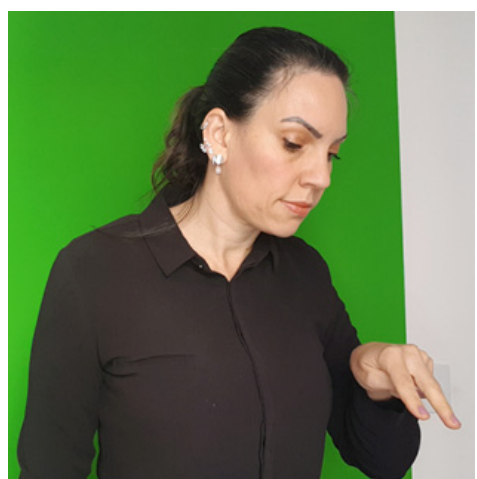

(C)

Figura 8. Pós-teste: produção da concordância verbal pela participante do Grupo Experimental Fonte: Dados da pesquisa

Essas amostras sinalizam para a interpretação de que o ensino explícito teve um pequeno efeito no uso da produção morfossintática; entretanto, como a melhoria foi distribuída entre os tipos verbais (concordância e manual) e entre as participantes, ele é entendido como não significativo. Se fosse observado o progresso na realização de outros tipos verbais ou se houvesse progresso cumulativo a uma ou outra participante, seria possível considerar uma evidência confirmatória da hipótese do efeito grande. Porém, como não é o caso, há que se averiguar se variáveis pessoais podem ter afetado positivamente o desempenho.

Assim, respondendo mais claramente à segunda pergunta de investigação, é possível afirmar que é incerto o efeito da instrução explícita da produção morfossintática da Libras no desempenho em L2.

\subsection{REFERENCIAÇÃO POR MEIO DO CORPO}

Por fim, tomarei os dados demonstrados no Quadro 7 para analisar o uso do elemento do ME que é de larga escala: 
Quadro 7. Desempenho em relação à referenciação por meio do corpo nas participantes da Dupla Experimental e da Dupla Controle no pré-teste e no pós-teste

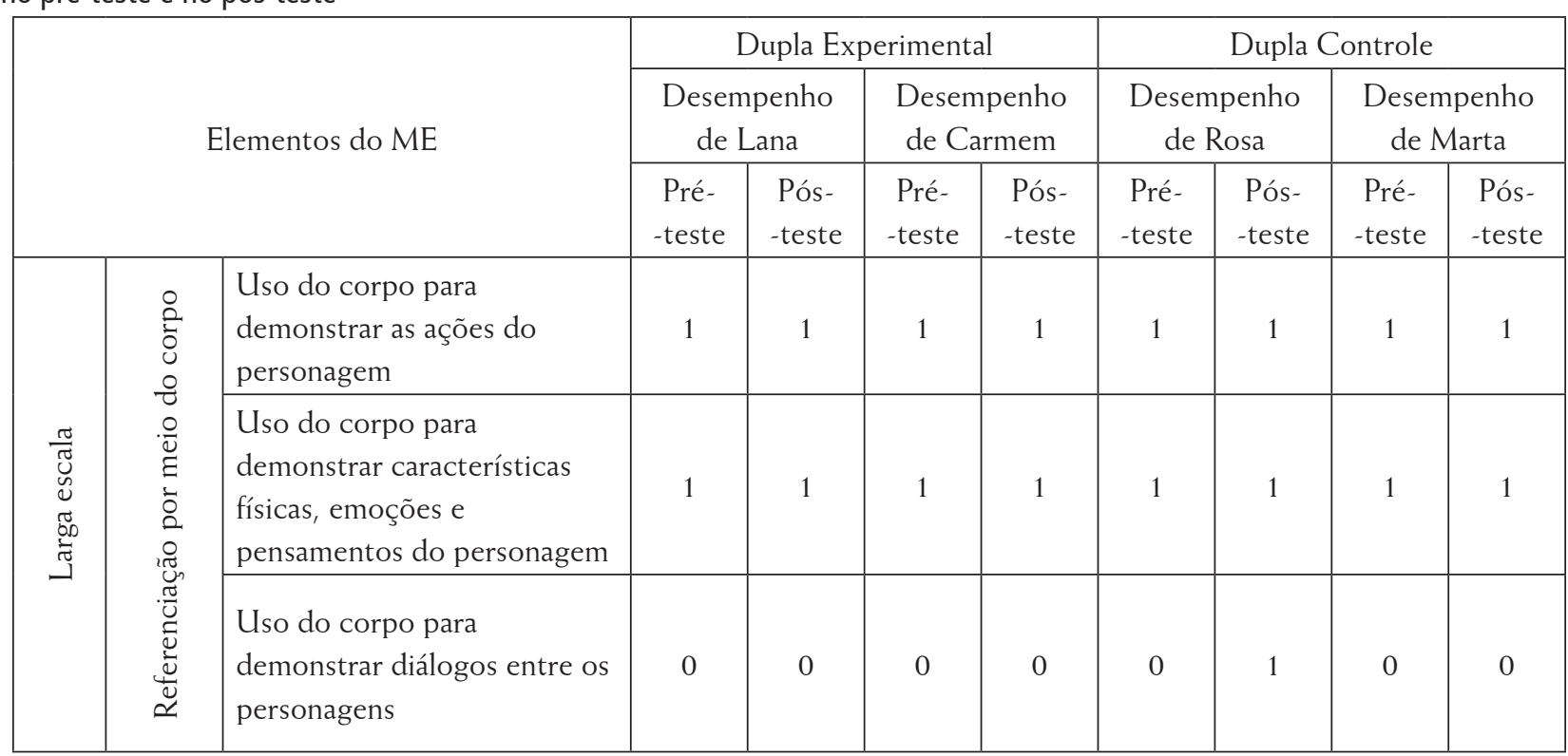

Fonte: Elaboração própria

Os dados expostos apresentam que o desempenho inicial das participantes da Dupla Experimental e da Dupla Controle é exatamente igual, inclusive com ausência do uso do corpo para produção de diálogos entre os personagens. A esse respeito é pertinente mencionar que a própria narrativa, por sua natureza, favoreceu a imitação de ações dos personagens. Para tanto, mesmo que as participantes tenham realizado a demonstração de características físicas, emoções e pensamentos de apenas um dos cinco personagens, houve atribuição de acerto (1) ao seu desempenho.

Os resultados do pós-teste evidenciam que, apesar de não haver verbalização no vídeo original, Rosa demonstrou um diálogo entre dois personagens: o menino e um dos adolescentes que o ajudaram. Um pequeno fragmento da conversa é demonstrado na Figura 9:

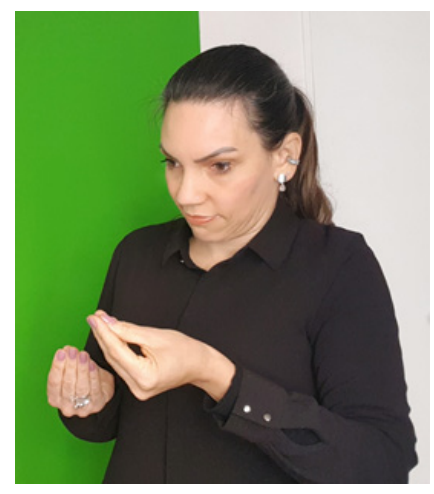

(A)

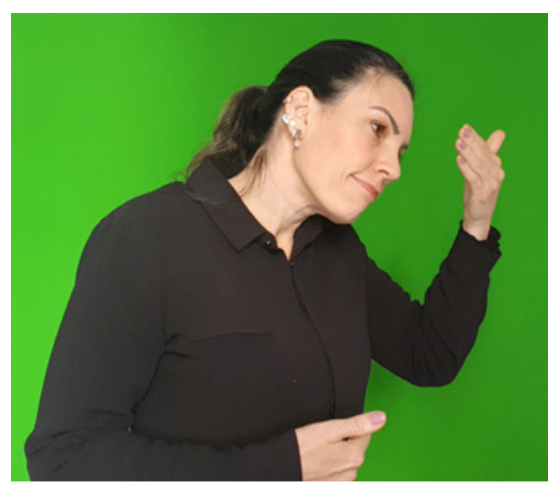

(B)

Figura 9. Realização de referenciação por meio do corpo em participante do Grupo Controle Fonte: Dados da pesquisa

A imagem (A) demonstra Rosa usando o seu corpo para simular a ação "entregar o chapéu", que foi realizada por um dos adolescentes. A imagem (B) demonstra que a sinalizante virou levemente o corpo em direção ao ponto que o personagem anterior (adolescente) havia sido referenciado e realizou o sinal de OBRIGAD@.

Considerando que Rosa teve contato com abordagem metodológica distinta conduzida por professora surda e obteve melhora do desempenho, é possível interpretar que a referenciação em larga escala, dada pelo uso do corpo, parece não ser sensível ao ensino explícito.

Respondendo mais claramente à terceira pergunta de investigação, é possível afirmar que não houve efeito da instrução explícita da referenciação por meio do corpo no desempenho em Libras como L2. 
Apesar dos resultados expressados até aqui, é possível perceber que o processo de instrução trouxe ganhos individuais às participantes, os quais estão sintetizados no Quadro 8.

Quadro 8. Os ganhos individuais das participantes

\begin{tabular}{|c|c|c|c|c|}
\hline Elementos do ME & $\begin{array}{c}\text { Ganho de } \\
\text { Lana }\end{array}$ & $\begin{array}{c}\text { Ganho de } \\
\text { Carmem }\end{array}$ & $\begin{array}{c}\text { Ganho de } \\
\text { Rosa }\end{array}$ & $\begin{array}{c}\text { Ganho de } \\
\text { Marta }\end{array}$ \\
\hline Verbo de concordância & & $\mathrm{X}$ & & $\mathrm{X}$ \\
\hline $\begin{array}{c}\text { Verbo espacial } \\
\begin{array}{c}\text { Uso do corpo para demonstrar diálogos entre } \\
\text { os personagens }\end{array}\end{array}$ & $\mathrm{X}$ & & & \\
\hline
\end{tabular}

Fonte: Elaboração própria

De todo modo, o desfecho final aponta que a hipótese do estudo foi refutada e, por conseguinte, é necessário tentar compreender as razões que levaram o ensino explícito do ME, uma eficiente ferramenta pedagógica, a não gerar grande efeito no desempenho de ouvintes sinalizantes de Libras como L2. Para tanto, considero que, em relação ao planejamento da intervenção, se o método dedutivo tivesse sido priorizado em vez do indutivo e se a variável "professor" tivesse sido controlada (de modo que não houvesse a diferença entre surdo e ouvinte) no GE e GC, a instrução poderia ter sido um pouco mais motivante aos aprendizes, e isso evitaria a ocorrência de um número baixo de participantes envolvidos até o término do experimento.

Quanto à aplicação, avalio que, pela forma como foi conduzida a instrução, os aprendizes não conseguiram internalizar e usar os elementos do ME. Isso porque o fato de a modelagem de várias estruturas complexas terem sido oferecidas conjuntamente acabou por sobrecarregar a memória de trabalho dos aprendizes (GAUTHIER, 2014) e caso um aluno não tenha lido as mensagens de alguns dias, por exemplo, teve que, posteriormente, lidar com um acúmulo expressivo de informações. Ademais, não houve oportunidade de repetição para que os aprendizes pudessem reforçar os padrões que levam à automatização.

Por fim, penso que a oferta da instrução explícita de forma remota, através do uso do aplicativo WhatsApp, não favoreceu o diálogo constante com os aprendizes, já que o contato era limitado ao envio de mensagens assíncronas. Sua participação, portanto, não foi ativa, e o fluxo comunicativo foi prejudicado. Caso houvesse momento de interação imediata por meio de outros meios tecnológicos, o efeito do ensino poderia ter sido mais bem avaliado. Essa falta de contextualização acabou por culminar em proposição de atividades de natureza diferente durante a prática independente e a prática guiada e uso excessivo da L1 dos alunos (português escrito). Na minha perspectiva, a falta de interação na língua-alvo (e de mais input) foi a razão que desencadeou os resultados exibidos.

\section{CONCLUSÃO}

Acredito que o pequeno número de participantes envolvidos no estudo e a falta de interação e contextualização causada pela escolha da ferramenta tecnológica podem ter mascarado o devido efeito do experimento. Por isso, concluo que há necessidade de aplicação do ensino explícito de forma presencial (ou com tecnologias que favoreçam a interação) para averiguação do uso do ME por aprendizes ouvintes.

Além disso, baseando-me em pressupostos teóricos, posso inferir que, apesar dos resultados, os alunos do GE estão um pouco mais atentos às realizações do $\mathrm{ME}$ e, pode ser que, muito em breve, ele emerja na sinalização em Libras. Obviamente, há necessidade de verificação posterior quanto ao desempenho para se conferir tal assumpção - se possível em contexto não condicionado - mas, ainda assim, parece-me legítimo afirmar que houve tomada de consciência dos elementos do ME.

\section{REFERÊNCIAS}

ALVES, U. K. (2004). O papel da instrução explícita na aquisição fonológica do inglês como L2: evidências fornecidas pela teoria da otimidade. Dissertação de Mestrado em Linguística Aplicada. Escola de Educação, UCPel, Pelotas. 
ALVES, U. K.; ZIMMER, M. C. (2005). A instrução explícita na aprendizagem da L2: uma abordagem conexionista. Nonada: Letras em Revista. n. 8, p. 221-232.

ANDRADE, O. G. (2014). A linguística contrastiva como ferramenta para o trabalho com a diversidade do português e do espanhol na formação inicial e continuada do professor de Línguas Estrangeiras/Adicionais. In: V Seminário Iberoamericano de Diversidade Linguística. Anais... Foz do Iguaçu: UNILA, p. 263-289.

DURÃO, A. B. A. B. (2004). A fossilização de erros: o estado da questão. Signum: Estudos da Linguagem. v. 3, n. 1, p. $47-61$.

FERREIRA-BRITO, L.; LANGEVIN, R. (1995). Sistema Ferreira Brito-Langevin de transcrição de sinais. In: FERREIRA BRITO, L. Por uma gramática de língua de sinais. Rio de Janeiro: Tempo Brasileiro.

GAUTHIER, C. (2014). O ensino explícito, aspectos teóricos e práticos. In: XVII Encontro Nacional de Didática e Prática de Ensino. Anais... Fortaleza: Universidade Estadual do Ceará, p. 1-16.

GEER, L. C.; KEANE, J. (2018). Improving ASL fingerspelling comprehension in L2 learners with explicit phonetic instruction. Language Teaching Research. v. 22, n. 4, p. 439-457.

HUMORISTA ZAIRE. (2020). Humoristazaire: \#piada_36: quarentena. (3m18s). Disponível em: https://www.youtube.com/ watch?v=04n0BQCdgyl. Acesso em: 18 jan. 2021.

INES DDHCT. (2020). Saber mais em Libras: Coronavírus - INES. (4m11s). Disponível em: https://www.youtube.com/ watch?v=0a42MkuaAB8\&t=1s. Acesso em: 18 jan. 2021.

TV INES. (2020). Saber Mais | Coronavirus (2m16s). Disponível em: http://tvines.org.br/?p=20494. Acesso em: 18 jan. 2021.

LIMA JÚNIOR, R. M. (2010). Uma investigação dos efeitos do ensino explícito da pronúncia na aula de inglês como língua estrangeira. Revista Brasileira de Linguística Aplicada. v. 10, n. 3, p. 747-771.

PICHLER, D. C.; KOULidOBROVA, H. (2015). Acquisition of sign language as a second language (L2). The Oxford Handbook of Deaf Studies in Language. p. 218-230.

RABASA FERNÁNDEZ, Y. (2011). A presença de erros na interlíngua de estudantes brasileiros aprendizes de espanhol. Revista Desempenho. v. 1, n. 16.

RODRIGUES, R. R.; PREUSS, E. O. (2018). Efeitos de instrução explícita na aquisição da entoação em espanhol/L2. Working Papers em Linguística. v. 19, n. 2, p. 214-238.

SILVA, L. da. (2018). Fluência de ouvintes sinalizantes de libras como segunda língua: foco nos elementos da espacialização. Tese de Doutorado em Linguística. Centro de Comunicação e Expressão, UFSC, Florianópolis.

SILVA, L. da. (2020). Aquisição de segunda língua: o estado da arte da Libras. Alfa. v. 64.

SILVA, L. da.; SILVA, A. R. (2019). Verbos manuais em libras: análise da produção em L2 e contribuições à prática pedagógica. Revista Diálogos. v. 7, n. 2, p. 201-225.

UNIVERSIDADE FEDERAL DE SANTA CATARINA. (2014). Corpus Libras. Disponível em: http://www.corpuslibras.ufsc. br. Acesso em: 26 jan. 2021.

WINSTON, E. (1995). Spatial mapping in comparative discourse frames. In: Emmorey, K.; Reilly, J. S. (ed.), Language, gesture, and space. New York: Psychology Press.

Recebido: 30/1/2021

Aceito: 26/6/2021

Publicado: 14/9/2021 